Preprint, for presentation at the 218 th ACS National Meeting to be held in New Orleans, LA, on August 22, 26, 1999.

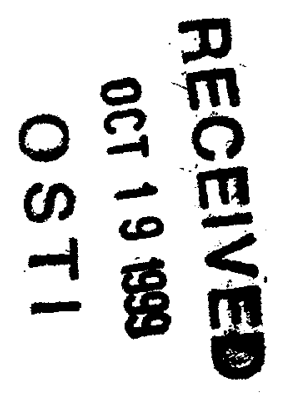

TIME RESOLVED SMALL ANGLE X-RAY SCATTERING REACTIVITY

STUDIES ON COALS, ASPHALTENES, AND POLYMERS*

R. E. Winans, S. Seifert, and P. Thiyagarajan ${ }^{\dagger}$

Chemistry Division and Intense Pulsed Neutron Source Division

Argonne National Laboratory

Argonne, IL 60439

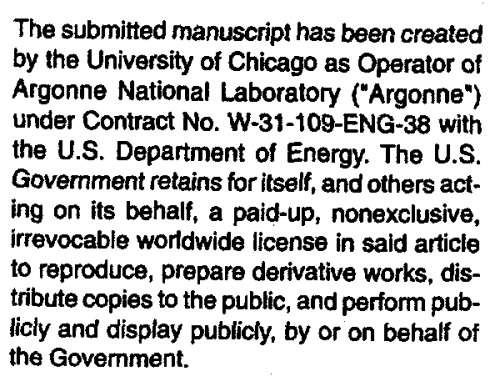

*This work was performed under the auspices of the Office of Basic Energy Sciences, Division of Chemical Sciences and Division of Materials Sciences, U.S. Department of Energy, under contract number W-31-109-ENG-38. 


\section{DISCLAIMER}

This report was prepared as an account of work sponsored by an agency of the United States Government. Neither the United States Government nor any agency thereof, nor any of their employees, make any warranty, express or implied, or assumes any legal liability or responsibility for the accuracy, completeness, or usefulness of any information, apparatus, product, or process disclosed, or represents that its use would not infringe privately owned rights. Reference herein to any specific commercial product, process, or service by trade name, trademark, manufacturer, or otherwise does not necessarily constitute or imply its endorsement, recommendation, or favoring by the United States Government or any agency thereof. The views and opinions of authors expressed herein do not necessarily state or reflect those of the United States Government or any agency thereof. 


\section{DISCLAIMER}

Portions of this document may be illegible in electronic image products. Images are produced from the best available original document. 


\title{
TIME RESOLVED SMALL ANGLE X-RAY SCATTERING REACTIVITY STUDIES ON COALS, ASPHALTENES, AND POLYMERS
}

\author{
R. E. Winans, S. Seifert, and P. Thiyagarajan ${ }^{\dagger}$
}

Chemistry Division and 'Intense Pulsed Neutron Source Division

Argonne National Laboratory, Argonne, IL 60439

Keywords: Argonne Premium Coals, pyrolysis small angle X-ray scattering

\begin{abstract}
The objective of this study is to examine changes in the structures of coals, asphaltenes, and polymers in situ with small angle X-ray scattering (SAXS) during thermal treatments. We have built a SAXS instrument at the Basic Energy Sciences Synchrotron Radiation Center at the Advanced Photon Source that allows us to obtain scattering data on very small samples and in the millisecond time domain. The Argonne Premium Coal samples, petroleum derived asphaltenes, and polymers with functionality to model fossil fuels were used in this study. The information that can be derived from these experiments includes: changes in fractal dimensionality, surface topology, and size and type of porosity. The information is correlated with other methods on the same samples.
\end{abstract}

\section{INTRODUCTION}

Small angle scattering is a good method to observe features such as porosity and surface properties of disordered systems over broad length scales. This non-destructive technique is useful for in situ analysis and with the advent of third general light sources with high photon flux, rapid data acquisition is possible. The nature of the porosity of a suite of 15 coals has been studied by SAXS and the results compared to adsorption techniques (1). Coal pyrolysis followed by gasification has been followed by SAXS. They found that upon pyrolysis there was an increase in micro and meso pores (2). SAXS investigation of pore sizes of Canadian coals and their chars showed that reactive chars from low rank coals have greater pore volumes compared to the coals, while the opposite effect is seen for less reactive chars from higher rank coals (3). The fractal pore structure of raw and heated brown coals was studied by SAXS (4). All of these were done with lab instruments. Synchrotron sources allowed faster data acquisition such that in situ experiment are facilitated such as the dynamics of solvent swelling (5). The Argonne coals have been looked at by a number of temperature programmed techniques such as TGA-FTIR (6), TGA-MS (7), Py-FIMS (8), Py HRMS (9), PMRTA (10), and IGC (11). These results will be used to help interpret data from temperature programmed(TP) SAXS of the Argonne Coals, resids, and polymers.

\section{EXPERIMENTAL}

The eight Argonne Premium Coal Samples were used without modification in this study (12). The ethylene [I] and oxymethylene [II] linked polymers have been used as possible models $(13,14)$. More recent studies have looked at ethylene linked benzene with [II] and without carboxylic acid groups [IV] $(15,16)$. The purpose of this later study was to examine the possible role of carboxylic acids to form crosslinks in low rank coal pyrolysis. The SAXS instrument was constructed at ANL and used on the Basic Energy Sciences Synchrotron Radiation Center CAT undulator beamline ID12 at the Advanced Photon Source (http://www.bessrc.aps.anl/).

Quartz capillaries $(1 \mathrm{~mm})$ were used to sample $5 \mathrm{mg}$ of -100 mesh coal or polymer. Scattering patterns were obtained as the sample is heated from $25-600{ }^{\circ} \mathrm{C}$. Monochromatic X-rays (8.5 - 23.0 $\mathrm{keV}$ ) are scattered off the sample and collected on a $19 \times 19 \mathrm{~cm}^{2}$ position sensitive two-dimensional gas detector. More recent data are taken using a 9-element mosaic CCD detector $(15 \times 15 \mathrm{~cm})$ with maximum of $3000 \times 3000$ pixel resolution. An advantage of this new detector is that unlike the wire detector, the full beam from the undulator can be used which gives a factor of 1000 increase in sensitivity. The scattered intensity has been corrected for absorption, the empty capillary scattering, and instrument background. The differential scattering cross section has been expressed as a function of the scattering vector $Q$, which is defined as $Q=(4 \pi / \lambda) \sin \theta$, where $\lambda$ is the wavelength of the $\mathrm{X}$-rays and $\theta$ is the scattering half angle. The value of $\mathrm{Q}$ is proportional to the inverse of the length scale $\left(\AA^{-1}\right)$. The instrument was operated with two different sample-to-detector distances, 68.5 cm to obtain data at $0.04<\mathrm{Q}<0.7 \AA^{-1}$ and $3740 \mathrm{~cm}$ to measure at $0.006<\mathrm{Q}<0.1 \AA^{-1}$.

\section{Small Angle X-ray Scattering}

A typical plot of the time temperature-resolved data for the pyrolysis of the Illinois No. 6 bituminous coal (APCS 3) is shown in Figure 1. These curves can be analyzed to determine size of features, 
topology, and changes in total scattering. At small $\mathrm{Q}$ in the Guinier region, the radius of gyration $\left(R_{g}\right)$, which is related to the size of the scattering features, can be determined. For example, $R_{g}$ for spheres can be determined from the slope of $\mathrm{I}(\mathrm{Q})$ vs $\mathrm{Q}^{2}$ in a $\mathrm{Q}$ region where $\mathrm{R}_{\mathrm{g}} \mathrm{Q} \leq 1.0$. Power law slope (fractal dimension) from the data, such as is shown in Figure 1, are used to describe the topology of the system. Finally, the invariant $\mathrm{Q}_{0}$ is calculated and is proportional to the fluctuation of the electron density in the system. Changes in the invariant are useful in monitoring topological changes in the sample, $Q_{0}=\int_{0}^{\infty} I(Q) Q^{2} d Q$. For example, the invariant goes to zero for a homogeneous system such as a solution of coal molecules that are truly soluble and not aggregated.

\section{RESULTS AND DISCUSSION}

The results from the TP SAXS are initially best understood by comparing them to results from other techniques and by looking at the various trends observed between the different rank premium coals. An example of the scattering curves as a function of $Q$ is shown in Figure 1 for the Illinois bituminous coal (APCS 3). To avoid confusion, a few selected curves are drawn to represent the changes seen a the sample heats up. An obvious feature that is seen for the low rank coals but is most pronounced with the Illinois coal is the increase in scattering over an intermediate temperature range. This result is best observed in the changes of the invariant with temperature which is shown in Figure 2. There is a rapid increase in the $\mathrm{Q}_{0}$ at $\sim 130^{\circ} \mathrm{C}$ where most likely water is being driven off. This has probably changed the surface area of the coal. These structural changes are common with the coals of $<80 \%$ carbon, but are not seen in the higher rank coals. However, the role of water release is not the only factor since the lignite and subbituminous coal have a greater water content and yet the effect is much less. The structure change is more than just a physical swelling of the structure since the free swelling index of this coals (4.8) is much less than, for example, the Upper Freeport (APCS 1), which has a FSI of 8.5 (12).

With the Upper Freeport, the increase in $\mathrm{Q}_{0}$ is not observed, but instead shows the transactions at the softening and fluidity points. Normally the approaches used to look at these transitions are plasticity or fluidity measurements and inverse gas chromatography (IGC). A comparison of the SAXS and ICC data are shown in Figure 3. One expects the IGC transition to occur at a lower temperature since the heating rate was in hours compared to the total heating time of $10 \mathrm{~min}$. for the SAXS data. However, note that the slope is the same (dashed line). In IGC, this slope is used to calculate the enthalpy of adsorption which for APCS 1 is $12.5 \mathrm{kcal} / \mathrm{mole}$ (11). These values increase with rank of the coal in the bituminous range. The trend in $\mathrm{Q}_{0}$ is also similar and is indicative of the increase in homogeneity of the system at these temperatures as the coals are becoming fluid. The low rank coals which do not become fluid show much different trends in $\mathrm{Q}_{0}$ at these higher temperatures.

The changes in the power law slope (fractal dimension, $\mathrm{d}_{\mathrm{f}}$ ) can be correlated with TGA results under the same heating rates. For bituminous coals, such as the Illinois No. 6 and Pocahontas, there is a reasonable correlation as shown in Figure 4. However, for the low rank coals, the changes in $d_{f}$ is much different and actually may have increased instead of decreasing with temperature as seen in the higher rank coals. One possible explanation for this is the fact that these coals are still early in the coalification process and what may be occurring is an accelerated coalification process. Part of this process may be the establishment of increased crosslinks instead of decreasing crosslinks, which normally occurs in the pyrolysis of bituminous coals. This has been suggested in other studies (15). Recently, model polymers with carboxylic acid functionality have been studied to try to understand this crosslinking phenomena. Later, we will discuss the results of TP SAXS on the polymer.

In Utah coals (APCS 6), the $d_{f}$ decreased at a much lower temperature than the other bituminous coals. This has also been observed for this coal by proton magnetic resonance thermal analysis (PMRTA). It has been suggested that the increased mobility observed is due to the liptinite macerals in this coal (which is rich with resinites, 75\%) at lower temperatures. Our SAXS data would confirm this conclusion. The volatile release of the coal is not unusual but the increase in extractability with heating is much greater than other bituminous coals of similar rank. The resinite must have a synergistic effect on overall thermal degradation of the macromolecular matrix.

To better understand TP SAXS results for the coal samples, four polymers which represent various potential structures and functionality in coals have been examined under the same conditions as the coal pyrolysis. For both the naphthalene based polymers $[\Pi]$ and $[\Pi]$, the structure changes at much lower temperatures than coals. However, as expected, the oxymethylene linked polymer [II] is the most reactive. In both polymers, a broad feature between $Q=0.1$ to 0.3 emerges at high temperature which would be the formation of larger polycyclic aromatics. The PyHRMS has shown that these polymers, especially [II] undergo secondary reactions to form strong Ar-Ar links which can lead to larger polycondensed aromatics. 
The polymers from ORNL behaved much differently, For [II] with carboxylic acid functionality, the $\mathrm{Q}_{0}$ did decrease but not nearly as much as seen in [I] and [I]]. The structure seen by SAXS for the hydrocarbon polymer [IV] appeared to be very stable over the temperature range studied even though it is known that the solubility increased with increasing temperature (15). However, up to about $475{ }^{\circ} \mathrm{C}$ these polymers showed no weight loss in TG analysis. The most direct comparison is between I and IV, which have the same linkages but differ in the aromatic ring, where the naphthalene [I] appears to be much more reactive.

\section{CONCLUSIONS}

Structural changes upon pyrolysis are observed in the SAXS data for coals and polymers. These changes can be correlated and contrasted with a number of other thermal analytical methods on the same coal and polymer samples. The results are very rank dependent with the lower rank coals showing variations over the entire temperature range. The naphthalene based polymers are much more reactive than the benzene-ethylene linked polymers and appear to give more secondary transformations.

\section{ACKNOWLEDGMENTS}

This work was performed under the auspices of the Office of Basic Energy Sciences, Division of Chemical Sciences and Division of Materials Sciences, U.S. Department of Energy, under contract number W-31-109-ENG-38. The support of the BESSRC staff is appreciated, especially Jennifer Linton and Mark Beno.

\section{REFERENCES}

1. Kalliat, M.; Kwak, C. Y.; Schmidt, P. W. In New Approaches in Coal Chemistry; Blaustein, B. D., Bockrath, B. C., Friedman, S., Eds.; ACS Symposium Series 169; American Chemical Society: Washington, D.C., 1981; pp. 3-22.

2. Foster, M. D.; Jensen, K. F. Fuel 1990, 69, 88-96.

3. Xu, Yingnian; Koga, Yoshikata; Watkinson, A. Paul. Fuel 1994, 73, 1797-801.

4. Johnston, P. R.; McMahon, P.; Reich, M. H.; Snook, I. K.; Wagenfield, H. K. J. Colloid Interface Sci. 1993, 155, 146-51.

5. Winans, R. E.; Seifert, S.; Thiyagarajan, P. Prepr. Pap. - Am. Chem. Soc., Div. Fuel Chem. 1999, 44, 149-152.

6. Solomon, P. R.; Serio, M. A.; Carangelo, R. M.; Bassilakis, R.; Gravel, D.; Baillargeon, M.; Baudais, F.; Vail, G. Energy Fuels 1990, 4, 319-33.

7. Yun, Y.; Meuzelaar, H. L. C.; Simmleit, N.; Schulten, H.-F. Energy Fuels 1991, 5, 22-29.

8. Simmleit, N.; Schulten, H.-R.; Yun, Y.; Meuzelaar, H. L. C. In Advances in Coal Spectroscopy; Meuzelaar, H. L. C., Ed.; Plenum Press: New York, 1992; pp. 295-339.

9. Winans, R. E. In Advances in Coal Spectroscopy; Meuzelaar, H. L. C., Ed.; Plenum Press: New York, 1992; pp. 255-274.

10. Sakurovs, R.; Lynch, L. J.; Barton, W. A. In Magnetic Resonance of Carbonaceous Solids; Botto, R. E., Sanada, Y., Eds.; Adv. Chem. Series 229; American Chemical Society: Washington, D.C.; 1993; pp. 229-251.

11. Neill, P. H.; Winans, R. E. In Inverse Gas Chromatography: Characterization of Polymers and Other Materials; Lloyd, D. R., Ward, T. C., Schreiber, H. P., Eds.; ACS Symposium Series 391; American Chemical Society: Washington, D.C., 1989; pp. 290-305.

12. Vorres, K. S. Energy Fuels 1990, 4, 420-426.

13. Winans, R. E.; Hayatsu, R.; Squires, T. G.; Carrado, K. A.; Botto, R.E. Prepr. Pap. - Am. Chem. Soc., Div. Fuel Chem. 1990, 35, 423-429.

14. Squire, K. R.; Solomon, P. R.; Carangelo, R. M.; DiTaranto, M. B. Fuel 1986, 65, 833-43.

15. Mungall, W. S.; Britt, P. F.; Buchanan, A. C., III. Prepr. Pap. - Am. Chem. Soc., Div. Fuel Chem. 1997, 42, 26-30.

16. Britt, P. F.; Mungall, W. S.; Buchanan, A. C. III. Energy Fuels 1998, 12, 660-661. 


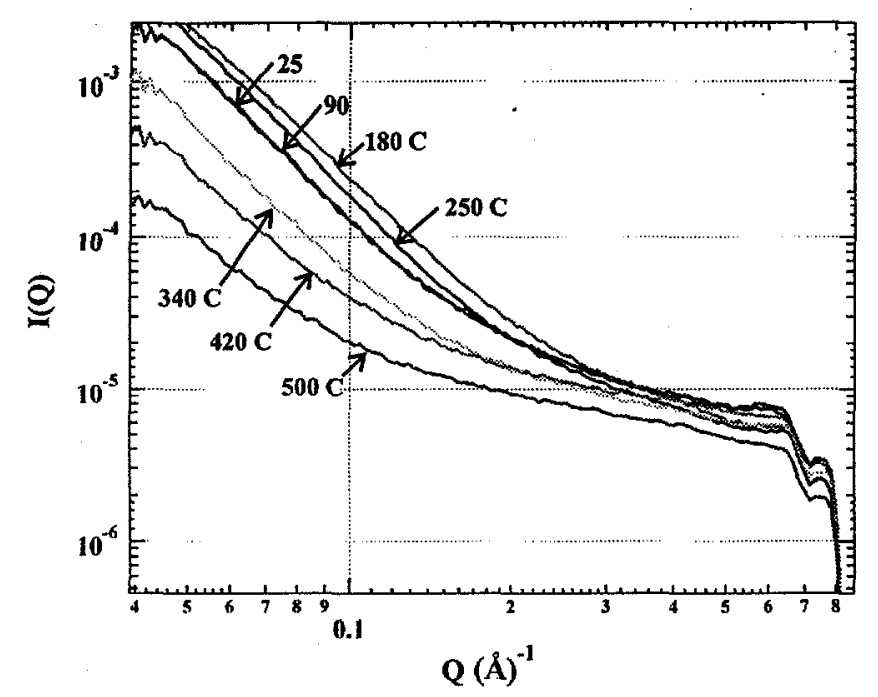

Figure 1. Selected temperatures for SAXS data from Illinois 6 pyrolysis.
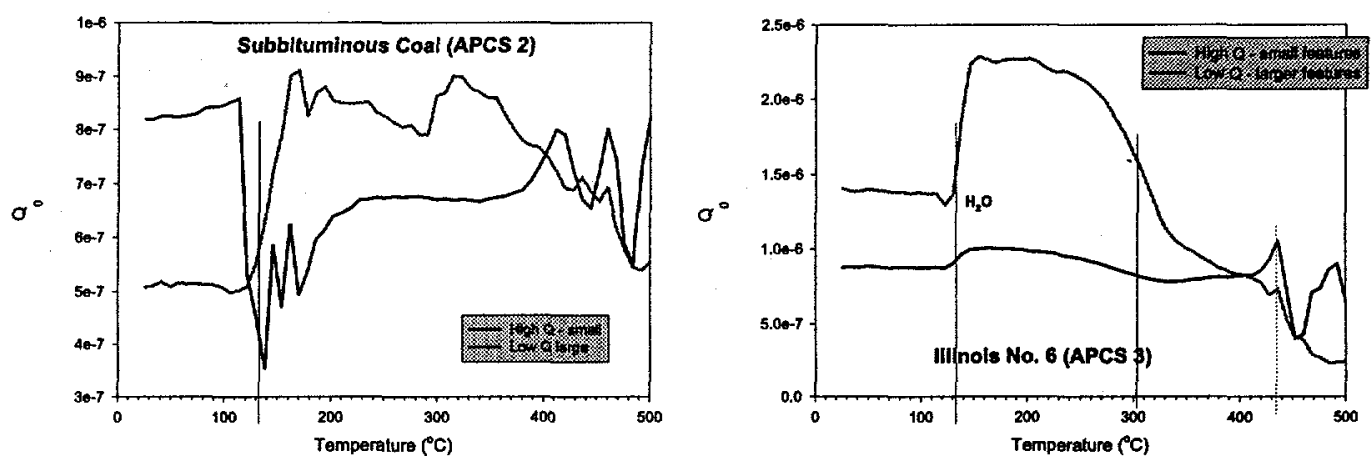

Figure 2. Invariant changes with pyrolysis.

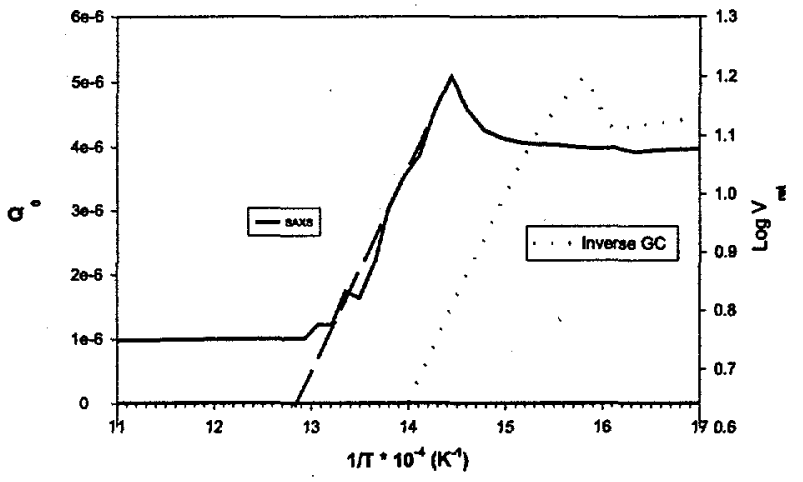

Figure 3. Comparison of SAXS with IGC data for the Upper Freeport coal (APCS 1).
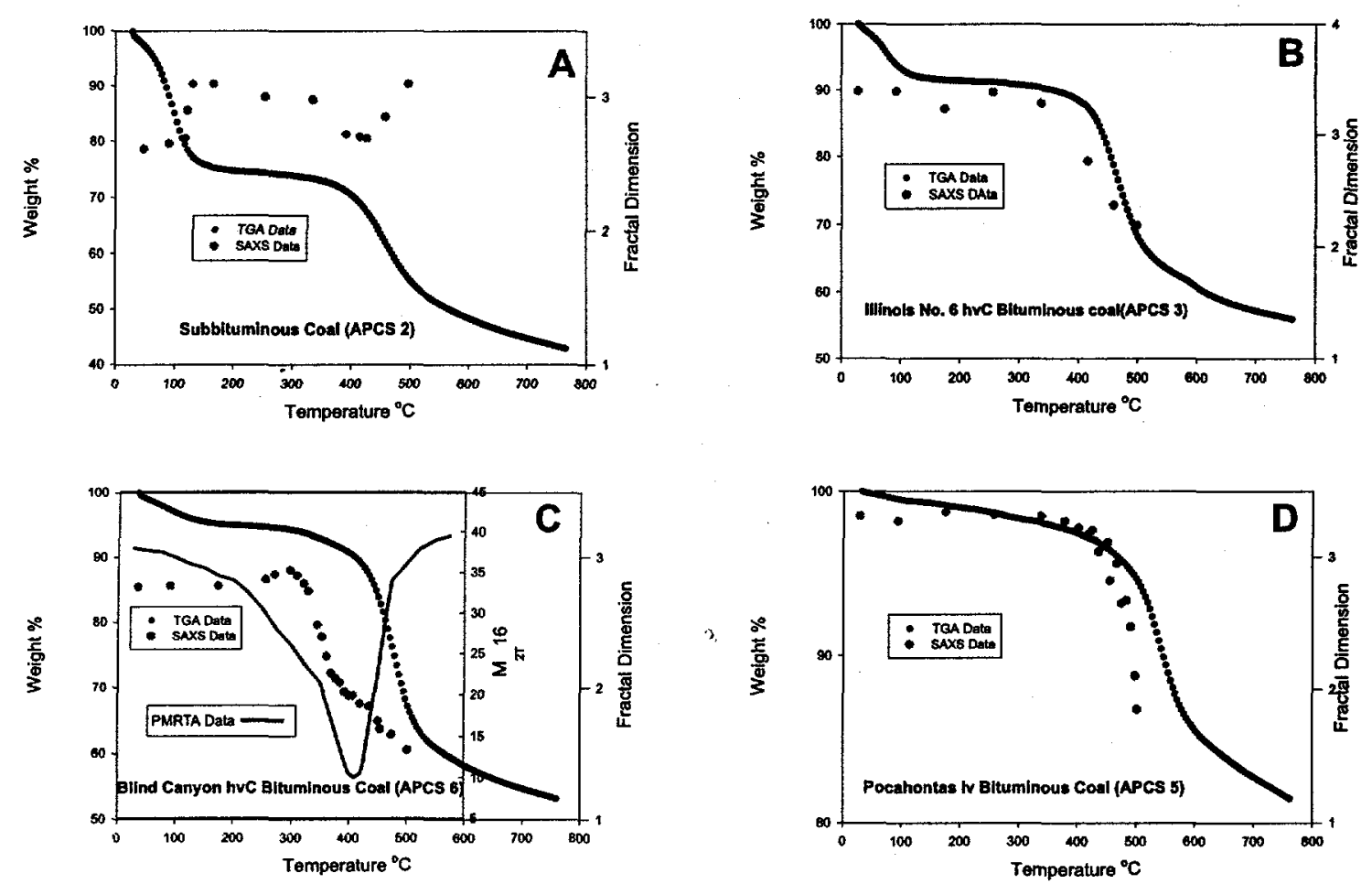

Figure 4. Comparison of TGA data with SAXS fractal dimension. 

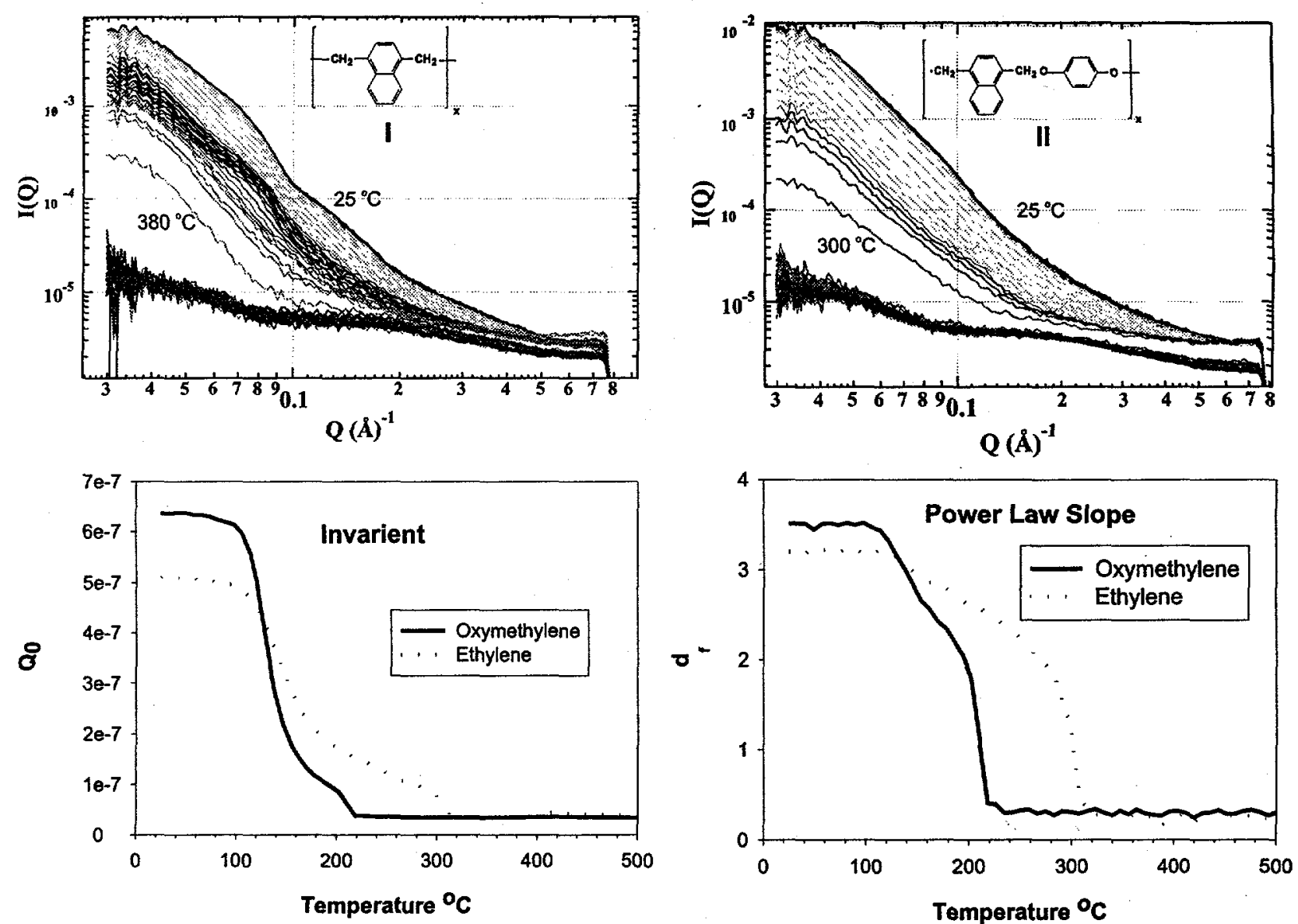

Figure 5. SAXS data for naphthalene polymers I and II with a comparison of invariants and power law slopes.
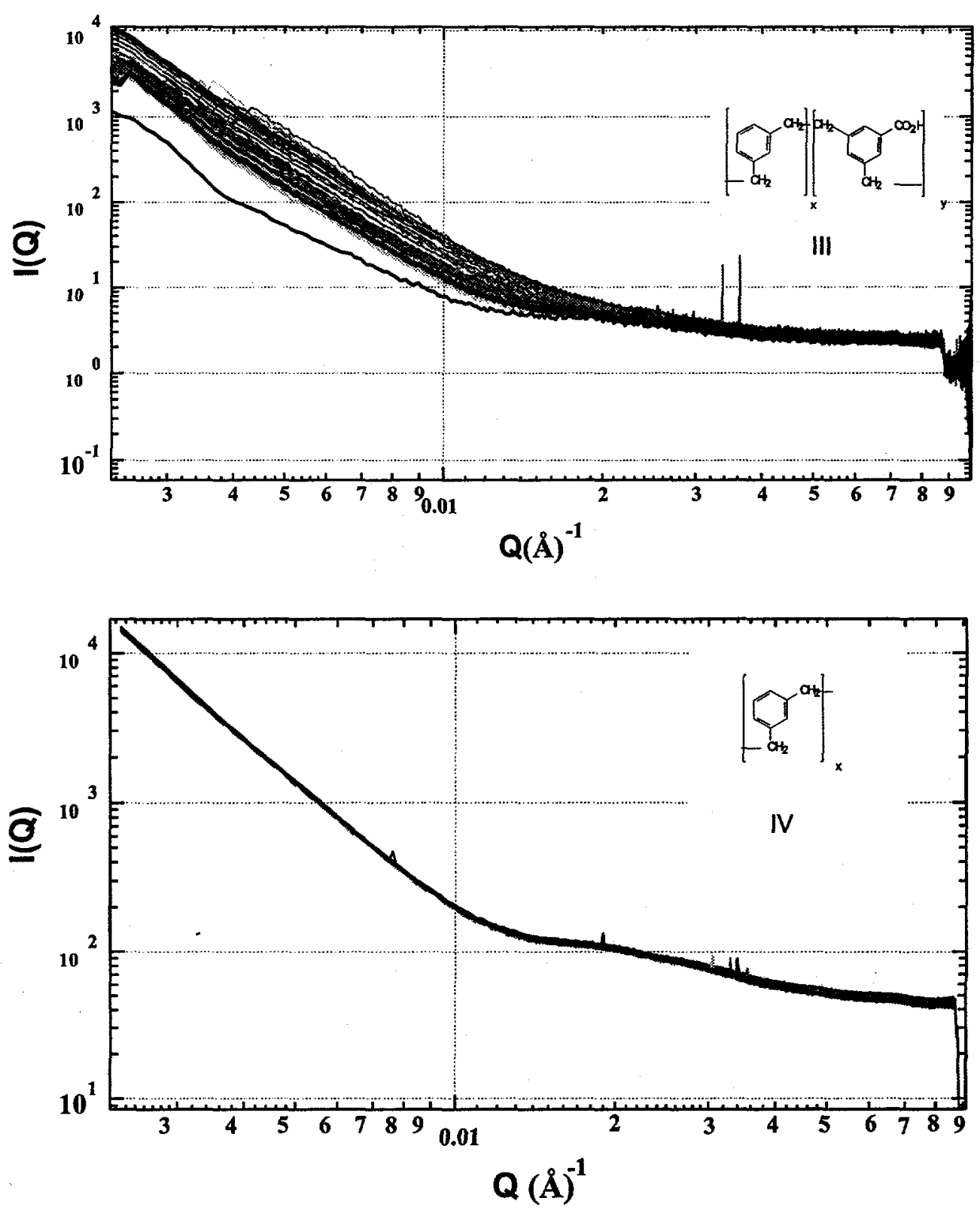

Figure 6. SAXS data for benzene polymers III and IV. 